\title{
A VULNERABILIDADE E O PACIENTE DA CLÍNICA ODONTOLÓGICA DE ENSINO
}

\section{Vulnerability and teaching odontologic clinic patients}

\author{
Evelise Ribeiro Gonçalves \\ Universidade Federal de Santa Catarina, Florianópolis/SC, Brasil. \\ eveliserg72@hotmail.com \\ Marta Inez Machado Verdi \\ Universidade Federal de Santa Catarina, Florianópolis/SC, Brasil. \\ verdi@mbox1.ufsc.br
}

\begin{abstract}
Resumo: As clínicas odontológicas de ensino são instituições de assistência que prestam atendimento com profissionais ainda em formação. Esta situação propicia o surgimento de conflitos e dilemas, principalmente porque a maioria das pessoas que procuram atendimento busca atenção odontológica especializada, que não é fornecida pela rede pública. Com o objetivo de identificar as questões éticas que permeiam o atendimento a pacientes em uma clínica odontológica de ensino, realizou-se uma pesquisa qualitativa de caráter exploratório descritivo com 10 professores do curso de odontologia de uma universidade pública federal. Foram investigadas as rotinas de acesso ao serviço e ao atendimento, marcados por situações peculiares, nas quais se percebe que as pessoas em busca de tratamento tornam-se freqüentemente vulneráveis, sofrendo, em decorrência, desrespeito em sua autonomia, como pacientes, cidadãos e seres humanos. Este artigo pretende chamar a atenção da classe acadêmica para o problema e reforçar a responsabilidade de todo o corpo docente dos cursos de odontologia na formação da competência ética dos futuros profissionais, bem como de sua postura frente aos pacientes atendidos nas clínicas de ensino.
\end{abstract}

Palavras-chave: Vulnerabilidade. Odontologia. Bioética. Clínicas odontológicas de ensino.

\begin{abstract}
The dental school clinics are unique assistance institutions providing health care through dental students. Moral conflicts and ethical dilemmas emerge specially as most people who attend these clinics are searching for specialized dental care not provided for, under Brazilian public health care. A qualitative, exploratory and descriptive research was performed at a dentistry course of a federal public university aiming to identify the ethical issues involved in patient attendance at the dental school clinic of this institution. The access and attendance routines were investigated, through which was clear that the people assisted are frequently put into vulnerable situations, and, as a result, their autonomy is not respected as patients, citizens and human beings. This article would like to bring this problem to the attention of the academy and to emphasize the responsibility all dental school professors have in the construction of the ethical competence of the future dentists as well as in their attitude toward the patients they assist at these institutions.
\end{abstract}

Key words: Vulnerability. Dentistry. Bioethics. Dental school clinics. 


\begin{abstract}
Ao se falar de vulnerabilidade e das questões políticas, sociais ou humanitárias que engloba, deve-se atentar para os padrões sociais de desigualdade nas condições de vida, de saúde e de acesso aos serviços de saúde, uma vez que são situações que propiciam o surgimento de pessoas ou populações vulneráveis (DINIZ, 2001). A versão revisada da Declaração de Helsinque traz um parágrafo que trata da questão:
\end{abstract}

"As necessidades particulares dos que apresentam desvantagens econômicas e médicas têm que ser reconhecidas. Também se requer especial atenção àqueles que não podem dar ou recusar o consentimento por si mesmos, àqueles que podem se sujeitar a dar consentimento em situações de dificuldade..." (WORLD MEDICAL ASSOCIATION, 2000).

O vulnerável sofre necessidades não atendidas, o que o torna frágil e predisposto a sofrer danos. Sujeitos vulneráveis têm que ser protegidos, enquanto os predispostos à vulnerabilidade precisam de assistência para remover a causa da sua fraqueza. Além da vulnerabilidade básica, intrínseca à existência humana, alguns indivíduos são afetados por circunstâncias desfavoráveis que os tornam ainda mais vulneráveis (KOTTOW, 2003).

A dificuldade de acesso à assistência odontológica caracteriza uma dessas circunstâncias, pois a cobertura da assistência odontológica pública brasileira não consegue suprir a demanda da população. Não só as vagas para atendimento são insuficientes, como os serviços prestados pelas unidades locais de saúde não atendem às necessidades por serviços odontológicos básicos ou especializados.

O Governo Federal, por meio do Programa Brasil Sorridente, e lançado em outubro de 2004, pretende investir em diversas ações em saúde bucal até o final de 2006. Entre elas está a construção e instalação de Centros de Especialidades Odontológicas - CEO, que vão prestar atendimento especializado à população (CONSELHO FEDERAL DE ODONTOLOGIA, 2004). Este programa está, no entanto, ainda em fase inicial de implantação, do que se depreende que boa parte da população continua desassistida.

As clínicas odontológicas de ensino são estabelecimentos vinculados aos cursos de odontologia das universidades, e, na sua maioria, são mantidas por verba pública. Essas clínicas prestam atendimento odontológico básico e especializado à população, por meio de profissionais ainda em formação, ou seja, os estudantes desses cursos. 
Segundo Beauchamp e Childress, "dentro de instituições de assistência médica que ensinam futuros profissionais através do atendimento a pacientes, surgem freqüentemente conflitos morais e dilemas éticos" (BEAUCHAMP \& CHILDRESS, 2002). Sua realidade peculiar pode contribuir para colocar as pessoas atendidas em condição vulnerável, já que as rotinas adotadas no cotidiano institucional referem-se a práticas que nem sempre têm relação direta com o tratamento do paciente, e sim, muito mais, com a formação do profissional e o cumprimento da produção acadêmica. Esses objetivos transformam as pessoas atendidas em objetos para o ensino aos estudantes. Em decorrência disso, as pessoas que procuram as clínicas de ensino dessas instituições, em busca de serviços que não lhes são fornecidos pela rede pública, tornam-se vulneráveis, e, conseqüentemente, sofrem desrespeito a sua autonomia.

Dito isso, é importante refletir sobre as diferentes questões éticas envolvidas na relação terapêutica protagonizada pelo paciente, o aluno e o professor. Dentre estes questionamentos, destacam-se: qual a autonomia dessas pessoas durante o atendimento? Podem recusar determinados procedimentos? Como se processa na relação paciente/aluno/professor o confronto de diferentes interesses: de um lado, a necessidade terapêutica; de outro, o interesse acadêmico? Há a supremacia de um em detrimento do outro, quando o interesse acadêmico prepondera sobre a vulnerabilidade dos pacientes, desrespeitando seu direito individual em nome do ensino?

Para responder a essas indagações, este estudo busca caracterizar diferentes situações nas quais o paciente da clínica odontológica de ensino é colocado em condição de vulnerabilidade.

\section{Metodologia}

Em 2004, foi realizada pesquisa de abordagem qualitativa e de caráter exploratório descritivo, junto a dez professores do curso de odontologia de uma universidade pública federal, sorteados dentre o corpo docente responsável pelas seguintes disciplinas: Cirurgia, Clínica Integrada, Dentística, Endodontia, Estomatologia, Odontopediatria, Ortodontia, Periodontia, Prótese Parcial e Prótese Total. As informações foram coletadas em entrevista semi-estruturada, incluindo nove perguntas abertas, gravadas em fitas-cassete, e, posteriormente, transcritas na íntegra. A técnica escolhida para a análise dos dados foi a análise de conteúdo proposta por Bardin (BARDIN, 1977). 
O projeto foi submetido à apreciação do Comitê de Ética em Pesquisa com Seres Humanos da Universidade Federal de Santa Catarina - UFSC, sendo aprovado sem restrições. A pesquisadora comprometeu-se a manter a identidade dos participantes em sigilo, com uso de codinomes. Foram utilizados os nomes de dez capitais européias colocadas em ordem aleatória, correspondendo cada uma delas a um entrevistado.

\section{A Vulnerabilidade do Paciente da Clínica Odontológica de Ensino}

Quando uma pessoa procura uma clínica odontológica de ensino, consente explícita e implicitamente com certas perdas de privacidade, relativas ao exame e ao tratamento odontológicos. Porém, essa decisão não concede nem implica em acesso irrestrito ao seu corpo. São poucos os pacientes, no entanto, que entendem a extensão da perda de privacidade que podem sofrer dentro da clínica odontológica de ensino, e, por outro lado, nem sempre os profissionais envolvidos no atendimento respeitam o limite desta perda, pautada entre outros aspectos, pelo princípio do respeito à autonomia.

Beauchamp e Childress colocam que o paciente deve ser sempre corretamente informado sobre a realidade da instituição e sobre os procedimentos a serem realizados, dando seu consentimento esclarecido e voluntário, e, também, nunca ser submetido a riscos desnecessários (BEAUCHAMP \& CHILDRESS, Op. cit.). Somente deste modo, não estarão sendo violados princípios éticos de relacionamento entre profissional e paciente. Porém, a realidade relatada pelos entrevistados explicitou algumas questões que claramente desrespeitam as pessoas atendidas na instituição pesquisada, colocando-as em condição de vulnerabilidade.

Uma primeira situação relatada pelos docentes, e que pode ser considerada um reflexo das desigualdades sociais que caracterizam a sociedade brasileira, é a luta por vagas para atendimento. Um dos docentes assim se manifestou: "É complicado [...] primeiro ele tem que entrar em uma competição pra poder conseguir uma vaga [...] houve uma época que existia um comércio [...] as pessoas vinham pra cá de madrugada, conseguiam a vaga e depois vendiam pra comunidade" (Roma).

Trindade e colaboradores ressaltam que, devido a fatores econômicos, sociais ou mesmo de necessidade especial à saúde bucal, observa-se crescente procura por atendimento odontológico nas clínicas de ensino (TRINDADE et al.,1999). Dessa forma, tem-se criado uma grande dificuldade para a obtenção 
de uma vaga para atendimento nessas instituições, sendo que a maioria dos que a conseguem, consideram o fato uma vitória, por mais contraditório que isso seja. Isso porque o serviço prestado ali é, na verdade, um direito adquirido das pessoas, uma vez que essas são instituições públicas, mantidas pela população com o pagamento de impostos. Apesar desse contra-senso, a realidade é que um grande número de pessoas procura as clínicas odontológicas de ensino das universidades em busca de serviços especializados "gratuitos" que não estão disponíveis na rede pública de atendimento e pelos quais não têm condição de pagar.

Uma vez tendo conseguido cadastrar-se na instituição, o paciente entra para uma fila de espera por atendimento em uma disciplina que faz o exame odontológico inicial e a anamnese, e que estabelece a prioridade de tratamento para cada paciente, encaminhando-o para outra lista de espera, a das disciplinas clínicas específicas. A partir daí, os pacientes deveriam ser chamados para atendimento seguindo a ordem dessa lista; no entanto, a realidade percebida pelos professores é outra. Perguntados se o sistema oficial de triagem de pacientes era respeitado, assim se manifestaram: "Não necessariamente. Até porque muitas vezes alguns pacientes nos vêm encaminhados por outros colegas de dentro da faculdade, que nos pedem ajuda para atender esse ou aquele paciente: um parente, um amigo" (Oslo).

Segundo Bellino, "um verdadeiro empenho ético deve garantir à ciência um máximo de liberdade compatível com o respeito devido aos outros valores em jogo [...] e essas regras valem não só para os peritos e cientistas, mas também para o homem comum" (BELLINO, 1997).

Privilegiar o atendimento de amigos, conhecidos e parentes de professores ou funcionários, expõe o uso de outros critérios para a distribuição de vagas, que não os previamente determinados pela instituição, ficando caracterizado o abuso da autoridade de professores e funcionários, que desrespeitam aqueles que aguardam por atendimento, evidenciando, também, a vulnerabilidade desses pacientes, que ficam aguardando o atendimento, pensando estar em uma lista de espera que, além de ser longa, parece também ser permeada por atalhos e desvios.

Além da questão do privilégio no atendimento a pessoas conhecidas, outras situações também desrespeitam a autonomia das pessoas que aguardam a chamada pelas disciplinas clínicas. Uma delas é a prioridade explícita que é dada por algumas das disciplinas ao atendimento de casos de interesse acadêmico, como relatou esse professor: 
"O paciente recebe uma orientação e fica sabendo que no momento que houver uma vaga para o que a gente precise a gente chama. Mas na dependência também daquilo que nos interessa. [...]. Porque eu sempre coloco para o pessoal: isso aqui antes de tudo é uma escola, não é um posto de atendimento" (Londres).

A percepção do professor deixa explícito que os casos de interesse acadêmico são tratados com prioridade, sobrepondo-se à lista de espera e às necessidades dos pacientes. Para legitimar tal regalia, utiliza-se como argumento a característica da instituição, formadora da clínica de ensino. É fato que esta instituição é uma escola, cuja finalidade é capacitar novos profissionais; entretanto, convém ressaltar que toda pessoa, na condição de paciente, ou seja, quando apresenta necessidades relativas a sua saúde, deve ser tratada para que tais necessidades sejam suprimidas. Ela não deve ser prejudicada ou preterida por não apresentar a "necessidade certa", que lhe possibilitaria obter o tratamento de maneira rápida, pois isso caracteriza desrespeito a um direito humano básico, que é o direito à saúde.

A importância e prioridade que são conferidas pela instituição à formação dos profissionais, e, conseqüentemente, ao cumprimento da produção acadêmica, ficam claras em outra situação, identificada nas práticas dos docentes: o uso de pacientes como "reserva". A dinâmica de trabalho adotada nas disciplinas clínicas prevê que o número de pacientes a terem acesso ao serviço deve corresponder ao número de alunos disponíveis para realizá-lo. Os "pacientes-reserva" são assim chamados porque representam um número excedente de pacientes, marcados para ficar aguardando uma chance de serem atendidos em caso, principalmente, da falta de algum paciente que foi agendado para aquele dia. Sobre isso, um docente assim se manifestou:

"Sempre se pede mais [...] um pouco não, normalmente o dobro, às vezes não dá para atender [...] não deu, aí eles voltam na semana que vem. [...] normalmente eles ficam chateados, mas normalmente são pessoas humildes que estão acostumadas com esse tipo de coisa" (Lisboa).

Chama a atenção a "coisificação" das pessoas, explícita nessa prática. Pela sua necessidade de tratamento, o paciente é visto como um meio que objetiva alcançar o fim proposto para a instituição, que é o atendimento a ser realizado pelo aluno. Segundo Fortes: 
"Todo ser humano, quando na posição de paciente, dever ser tratado em virtude de suas necessidades de saúde e não como um meio para a satisfação de interesses de terceiros, da ciência, dos profissionais de saúde ou de interesses industriais e comerciais" (FORTES, 2002).

Além disso, a situação caracteriza também desrespeito à autonomia do paciente, a quem não é dada nenhuma informação que lhe possibilite tomar uma decisão com pleno conhecimento de causa.

O uso do Termo de Consentimento Livre e Esclarecido é frequentemente associado ao respeito à autonomia do paciente. Em teoria, deve proteger o sujeito na pesquisa ou no tratamento, informando-o sobre os procedimentos a serem realizados e seus objetivos, buscando desta forma respeitar a vontade do indivíduo em consentir ou não com realização de determinada ação. A clínica odontológica de ensino pesquisada adota como prática comum o uso de um Termo de Autorização para diagnóstico e tratamento, localizado no rodapé da ficha cadastral do paciente junto à instituição. A sua assinatura, que acontece quando o paciente é examinado pela primeira vez, é prérequisito para que seja encaminhado para as disciplinas clínicas. Um docente se manifestou sobre o fato: "[...] ele quer ser atendido, então ele vai assinando da mesma forma que eu assinei o teu consentimento informado [...] a maioria dos pacientes que vão ler o consentimento informado, eles dão uma "passada" e assinam [...]" (Copenhague).

O termo em questão concentra, em algumas linhas, um grande número de procedimentos e ações a serem realizadas, com as quais o paciente teoricamente consente ao assinar, mesmo quando se encontra em situação de vulnerabilidade social. Segundo Zoboli e Fracolli, tal situação inclui, entre outros fatores, a pobreza, as desigualdades sociais e de acesso às ações e serviços de saúde e educação (ZOBOLI \& FRACOLLI, 2001). Frente à vulnerabilidade social, deve-se questionar se o sujeito que enfrentou dificuldades para conseguir acesso aos serviços de saúde, é verdadeiramente livre para exercer sua opção autônoma, especialmente quando teme que sua recusa em assinar um termo de consentimento possa resultar na perda da vaga para atendimento.

Além disso, freqüentemente há um longo período, de meses e até anos, de espera entre a assinatura da autorização e o atendimento propriamente dito, devido à grande demanda por vagas. O paciente acaba, portanto, consentindo com uma variedade de procedimentos em relação aos quais dificilmente pode prever a efetiva realização. 
A maneira como o Termo de Autorização para tratamento é utilizado na instituição, como mera formalidade burocrática, suscita o questionamento sobre até que ponto os pacientes estão realmente informados e de acordo com a realização de todos os procedimentos. Para avaliar isso, procurou-se saber se existiam outras formas de informar os pacientes e de obter seu consentimento voluntário quando realizados procedimentos terapêuticos e tomadas imagens fotográficas. A respeito disso, alguns docentes assim se manifestaram: "Infelizmente não. Na verdade a única preocupação é com o diagnóstico, planejamento e tratamento, e não se presta nenhum outro tipo de esclarecimento adicional ao paciente" (Estocolmo); “ “...] eu não faço esse tipo de coisa, mas eu acho que não é pedido o consentimento da pessoa. Acha um caso interessante, alguém pega a máquina, bate a foto e pronto" (Berlim).

O princípio da autonomia é desrespeitado devido à falta de informação do paciente em relação ao procedimento que se pretende fazer e à ausência do consentimento livre, esclarecido e voluntário, específico para cada procedimento. Vários professores argumentaram que os pacientes já haviam dado consentimento quando assinaram a autorização para tratamento. No entanto, deve-se atentar para o conflito criado pelo uso da autorização para tratamento como forma única de esclarecimento e concordância do paciente com a realização de todos os procedimentos que vão ser feitos na clínica, incluindo as fotografias. Além disso, essa autorização, além de não ser um documento específico, não contempla informações suficientes sobre os procedimentos que serão realizados e, como já foi dito, é apresentada ao paciente muito tempo antes da realização do atendimento.

A dificuldade em conseguir atendimento parece gerar nas pessoas o medo constante da perda da vaga, tornando-as vulneráveis. Em função disso, acabam assinando - muitas vezes sem saber com o que estão consentindo - a autorização para tratamento e se submetendo no cotidiano das clínicas de atendimento a todo e qualquer procedimento. Essa situação caracteriza a restrição da liberdade de manifestação dos pacientes atendidos, que fica explícita na fala deste docente:

“O paciente praticamente não fala nada, [...], porque ele já estava esperando há muito tempo, então imagina se ele começar a fazer certos questionamentos que seriam normais, ele pensa que naturalmente vai perder a vaga. [...]" (Copenhague). 
Por fim, uma situação que constantemente coloca os pacientes atendidos pela clínica odontológica de ensino em condição de vulnerabilidade é a prática, comum em algumas disciplinas, de exigir dos alunos o cumprimento de produção acadêmica mínima como requisito para a aprovação: “[...] o aluno tem que ter uma certa produção dentro da disciplina e ele pode ser penalizado pela recusa do paciente e ele vai ter que ir atrás de outra forma pra compensar essa perda" (Paris). A mesma situação é relatada por outro docente:

"Na nossa disciplina nós temos muito cuidado em não exigir dos nossos alunos produção mínima, porque pode ser que ele chegue no final e não tenha produzido exatamente o número certo de procedimentos que a gente considere ideal e por isso a gente atribua a ele uma nota inferior à de um indivíduo que tenha feito desnecessariamente o dobro" (Estocolmo).

A vulnerabilidade do paciente fica explícita se considerarmos que, da mesma forma que algumas disciplinas se preocupam em coibir a "inclinação" de certos alunos em "sobretratar" alguns pacientes para cumprir a meta estipulada pela disciplina, outras podem não ter a mesma orientação ou ter um corpo docente menos atento a esses acontecimentos.

Os pacientes confiam nos estudantes de odontologia e sempre esperam que eles atuem em nome da sua saúde bucal. Quando o estudante sugere um tratamento, que seja o indicado para o caso e também seja "útil" para completar a sua produção, ele não está necessariamente violando a autonomia do paciente ou ferindo o seu próprio dever de beneficência; mas, para que isso se configure, o paciente deve estar informado a respeito de toda a situação e realmente dar seu consentimento voluntário para que o tratamento aconteça (VAN DAM \& WELIE, 2001). Esses autores vão ainda mais longe, dizendo que, ao não informar o paciente sobre essa situação, os estudantes, e por conseqüência, os professores que os orientam, agem da mesma forma desonesta que pesquisadores que não esclarecem corretamente os sujeitos de pesquisa ou os profissionais que tentam convencer pacientes a fazer tratamentos caros e desnecessários.

Todas as situações visualizadas nesta pesquisa, por mais questionáveis, constrangedoras e injustas, fazem parte do cotidiano de instituições similares à pesquisada neste trabalho, remetendo a uma citação de Foucault, que pode ser interpretada para a realidade pesquisada por este estudo. Ele questiona: 
"Com que direito se pode transformar em objeto de observação clínica um doente ao qual a pobreza obrigou a solicitar a assistência hospitalar? Ele requer um auxílio do qual é o sujeito absoluto na medida em que este foi criado pra ele; mas agora lhe é imposto um olhar do qual ele é objeto, e um objeto relativo, pois o que se decifra nele está destinado a um melhor conhecimento dos outros" (FOUCAULT, 1987).

\section{Considerações Finais}

A vulnerabilidade intrínseca à existência humana é, até certo ponto, protegida pela sociedade. Afora essa vulnerabilidade, os seres humanos são afetados por vulnerabilidades circunstanciais, em decorrência da pobreza, da falta de acesso a serviços de saúde e da discriminação. Essas situações impedem as pessoas de terem suas necessidades atendidas, predispondo-as a infortúnios adicionais. A bioética tem particular preocupação com essa vulnerabilidade secundária e circunstancial devido aos riscos que correm as pessoas vulneráveis de serem prejudicadas pela exploração advinda de ações biomédicas realizadas por profissionais da saúde.

A formação de futuros profissionais é a importante missão das instituições de ensino. No entanto, quando essa formação envolve atendimento odontológico prestado à comunidade e realizado por estudantes, a situação assume características diferentes da simples democratização de informações e de conhecimento, havendo o risco de que se estabeleçam conflitos morais e dilemas éticos devido à submissão dessas pessoas à condição de objeto de ensino para os futuros profissionais.

É importante sublinhar que o atendimento prestado pelas clínicas odontológicas de ensino representa, para parte da população brasileira, a única chance de acesso a determinados serviços essenciais, que não são fornecidos pela rede pública de atendimento. Tal situação pode tornar essas pessoas vulneráveis, o que freqüentemente ocorre, pois elas acabam se submetendo a qualquer situação para suprir sua necessidade de saúde, sendo, então, desrespeitadas na sua autonomia, como pacientes, cidadãos e seres humanos.

Assim, vale ressaltar que todo o corpo docente do curso de odontologia tem grande responsabilidade na construção da competência ética dos futuros odontólogos e na sua postura frente aos pacientes, que vivenciam, mesmo que por período determinado, a condição de objeto de ensino para os profissionais em formação. Esta condição, além de questionável, não justifica desrespeitos a sua dignidade, valor primeiro e fundamental da vida humana. 


\section{Referências Bibliográficas}

BARDIN, L. Análise de conteúdo. Lisboa, Edições 70. 1977.

BELLINO, F. Fundamentos da bioética. Aspectos antropológicos, ontológicos e morais. Bauru, EDUSC. 1997.

BEAUCHAMP, T. \& CHILDRESS, J. Princípios da ética biomédica. São Paulo, Ed. Loyola. 2002.

BRASIL. Ministério da Saúde. Conselho Nacional de Saúde. Comissão Nacional de Ética em Pesquisa. Normas para Pesquisa Envolvendo Seres Humanos (Res. CNS 196/ 96 e outras) Brasília: Ministério da Saúde, 2002.

CONSELHO FEDERAL DE ODONTOLOGIA, ano 12, n. 61, jul-ago., Rio de Janeiro. 2004.

CONSELHO FEDERAL DE ODONTOLOGIA, ano 12, n. 62, set-out,, Rio de Janeiro. 2004 .

DINIZ, D. A vulnerabilidade na bioética. In: COSTA, S. I. \& DINIZ, D. (Orgs.). Bioética: ensaios. Brasília: Letras Livres: 27-32, 2001.

FORTES, A. P de C. Ética e saúde. São Paulo, EPU, 1ª reimpressão, 2002.

FOUCAULT, M. El nacimiento de la clínica. México, Siglo XXI. 1987.

KOTTOW, M. Bioética e política de recursos em saúde. In: GARRAFA, V. \& COSTA, S. I. F. (Orgs.). A bioética no século XXI. Brasília, Editora Universidade de Brasília: 67-75. 2000.

TRINDADE, O. \& RAMOS, D. Análise das rotinas adotadas nos serviços de triagem de instituições de ensino odontológico para atendimento e encaminhamento de pacientes: aspectos éticos. Revista da Pós-Graduação da Faculdade de Odontologia da USP, São Paulo, Universidade de São Paulo, 6: 291-297.1999.

WORLD MEDICAL ASSOCIATION. Declaration of Helsinki, Paragraph 2, 2000.

ZOBOLI, E.L. C. P. \& FRACOLLI, L. A. Vulnerabilidade do sujeito de pesquisa. Cadernos de Ética em Pesquisa, Brasília, Ano IV(8): 20-21. 2001.

VAN DAM, S. \& WELIE, J. Requirement-driven dental education and the patient's right to informed consent. Journal of American College Dentistry, 68(3):40-47, 2001.

Recebido em 11/6/2005

Aprovado em 9/8/2005 